\title{
Nove vrste i nomenklaturne preinake u popisu flore mahovina Hrvatske - 1
}

\author{
VEDRAN ŠEGOTA ${ }^{1}$, ANJA RIMAC, ANTUN ALEGRO
}

Sveučilište u Zagrebu, Prirodoslovno-matematički fakultet, Biološki odsjek, Botanički zavod, Marulićev trg 20/II, HR-10000 Zagreb, Hrvatska

*Autor za dopisivanje / corresponding author: vedran.segota@biol.pmf.hr

Tip članka / article type: kratko stručno priopćenje / short professional communication Povijest članka / article history: primljeno / received: 15.12.2020., prihvaćeno / accepted: 22.12.2020. URL: https://doi.org/10.46232/glashbod.8.2.6

Šegota, V., Rimac, A. Alegro, A. (2020): Nove vrste i nomenklaturne preinake u popisu flore mahovina Hrvatske - 1. Glas. Hrvat. bot. druš. 8(2): 113-123.

\section{Sažetak}

Popis flore mahovina Hrvatske dopunjen je s 27 novih svojti (tri rožnjače, tri jetrenjarke i 21 prava mahovina) pronađenih u posljednjih pet godina. Vrste su unesene u novi modul Mahovine u bazi podataka Flora Croatica (https://hirc.botanic.hr/fcd/beta/Mahovine), u kojem je dosad dostupno ukupno 26674 nalaza mahovina iz 150 literaturnih referenci te manjeg broja opažanja, a uskoro započinje i digitalizacija mahovinskih herbarijskih zbirki. U Hrvatskoj je do sada zabilježeno ukupno 798 svojti mahovina.

Ključne riječi: flora, mahovine, nove vrste

Šegota, V., Rimac, A. Alegro, A. (2020): New species and nomenclatural changes in the checklist of the Croatian bryophyte flora - 1. Glas. Hrvat. bot. druš. 8(2): 113-123.

\section{Abstract}

The checklist of the Croatian bryophyte flora has been updated with 27 new taxa (three hornworts, three liverworts and 21 mosses), found during the last five years. The species have been imported in the new module Bryophytes within Flora Croatica Database (https:/hirc.botanic.hr/fcd/beta/Mahovine). In total 26674 bryophyte records are available within this module, originating from 150 literature references, and from smaller number of observations. Digitalization of the bryophyte herbarium collections is soon to begin. A total of 798 bryophyte taxa have been recorded in Croatia to this day.

Keywords: bryophytes, flora, new species

\section{Anthoceros agrestis Paton}

Mjesto prvog objavljivanja: J. Bryol. 10: 257.f. 1 (1979)

Sinonimi: Anthoceros punctatus L. subsp. agrestis (Paton) Damsh., Ill. Fl. Nord. Liverw. Hornw. 800 (2002); A. punctatus L. var. douinii (R.M.Schust.) Damsh., Ill. Fl. Nord. Liverw. Hornw. 802 (2002); A. nagasakiensis Steph., Sp. Hepat. (Stephani) 5: 1005 (1916); Aspiromitus punctatus (L.) Schljakov subsp. agrestis (Paton) R. M. Schust, Hepat. Anthocerotae N. Amer. 6: 797 (1992) 
Nalazišta u Hrvatskoj: selo Nebojan kraj Petrinje (preuzeto iz Rimac i sur. 2019a)

Ovo je jedna od malobrojnih vrsta rožnjača u Hrvatskoj, prvi puta pronađena 2013. na otvorenom tlu na plantaži lješnjaka, a zatim i 2018. na otvorenom tlu u dvorištu u selu Nebojan (Sl. 1A). Vrsta dolazi i na obradivim površinama i strništima, u vrtovima, vlažnim livadama, uz jarke i staze, na otvorenom, vlažnom, uglavnom ilovastom tlu. Raste u malenim svijetlozelenim rozetama valovitih rubova, koje nose uspravne sporofite nalik rogovima. Vrsta pripada europskom tempratnom elementu, široko je rasprostranjena, ali relativno rijetko bilježena. Trenutno je jedini poznati predstavnik roda Anthoceros u hrvatskoj flori.

\section{Notothylas orbicularis (Schwein.) Sull.}

Mjesto prvog objavljivanja: Amer. J. Sci. Arts 1: 75 (1845[1846])

Sinonimi: Targionia orbicularis Schwein., Spec. Fl. Amer. Crypt. 23 (1821); Carpobolus orbicularis (Schwein.) Schwein., J. Acad. Nat. Sci. Philadelphia 2: 366 (1822); Notothylas joponica Horik., Sci. Rep. Tôhoku Imp. Univ., Ser. 4, Biol. 4: 425 (1929)

Nalazišta u Hrvatskoj: selo Nebojan kraj Petrinje (preuzeto iz Rimac i sur. 2019a)

Ovo je vrlo rijetka rožnjača kozmopolitske rasprostranjenosti koja preferira ne tako rijetka staništa pa dolazi na otvorenim ilovastim i glinovitim tlima obradivih površina i strništa. Ovo je Natura 2000 vrsta čiji su rijetki nalazi u Europi do 2018. bili ograničeni na njezin središnji dio pa nalaz u Hrvatskoj predstavlja najjužniji nalaz u Europi, kao i prvi nalaz vrste na Balkanskom poluotoku. Zanimljivo, vrsta je pronađena u dvorištu obiteljske kuće na otvorenom ilovastom tlu prošlogodišnjih krtičnjaka s kojih je uklonjen višak tla, a ostatak je zbijen tijekom održavanja travnjaka (Sl. 1B). Vrsta je rasla s još dvije rijetko viđene rožnjače, također tada po prvi puta zabilježene za floru Hrvatske - Anthoceros agrestis Paton i Phaeoceros carolinianus (Michx) Prosk.

\section{Phaeoceros carolinianus (Michx) Prosk.}

Mjesto prvog objavljivanja: Bull. Torrey Bot. Club 78: 347 (1951)

Sinonimi: Anthoceros carolinianus Michx., Fl. Bor.Amer. 2: 280 (1803); A. laevis L. var. carolinianus (Michx.) Lindb., Moss. Dillen. Hist. Musc. 37 (1883); Phaeoceros laevis (L.) Prosk. var. carolinianus (Michx.) Augier, Fl. Bryophyt. 187 (1966)

Nalazišta u Hrvatskoj: selo Nebojan kraj Petrinje (preuzeto iz Rimac i sur. 2019a)

Ovo je relativno rijetka ili vjerojatnije previđena vrsta rožnjače, koja je 2018. pronađena zajedno $s$ već spomenutima vrstama rožnjača Anthoceros agrestis i Notothylas orbicularis na otvorenom ilovastom tlu na travnjaku obiteljske kuće (Sl. 1C). Rasla je u tamnozelenim rozetama jednostavnih rubova koje su nosile broje sporofite. Vrsta je europski tempratni element, ima diskontinuiranu cirkumpolarnu rasprostranjenost te se javlja i na južnoj polutci. Kao i sve ostale predstavnice rožnjača u Hrvatskoj, i ova vrsta preferira staništa kao što su obradive površine i strništa.

\section{Petalophyllum ralfsii (Wills.) Nees et Gottsche}

Mjesto prvog objavljivanja: Nov. Stirp. Pug. 8: 30 (1844)

Sinonimi: Diplolaena lyellii (Hook.) Dumort. var. lamellata (Nees) Pearson, Hepat. Brit. Isl. 430 (1901); Diplolaena lyellii (Hook.) Dumort. f. lamellata Nees, Naturgesch. Eur. Leberm. 3: 345 (1838); Fossombronia corbuliformis Trab., Atlas Fl. Alger 1: 7 (1886); Jungermannia ralfsii Wilson, Engl. Bot. pl. 2874 (1843); Petalophyllum lamellatum (Nees) Lindb., Not. Sällsk. Fauna Fl. Fenn. Förh. 13: 390 ( 1874); Codonia ralfsii (Wilson) Dumort, Bull. Soc. Roy. Bot. Belgique 13: 16 (1874)

Nalazišta u Hrvatskoj: Donji Kamenjak u Istri (preuzeto iz Šegota i sur. 2020b) 
Ovo je rijetka atlantsko-mediteranska vrsta jetrenjarke s najvećim populacijama na Britanskom otočju i vrlo rijetkim i uglavnom starim nalazima duž obale Sredozemnog mora. Na Balkanskom poluotoku poznata je jedino s dva lokaliteta na Peloponezu. Početkom 2020. mala populacija ove vrste pronađena je na Donjem Kamenjaku na otvorenom tlu uz šumsku sastojinu alepskog bora i hrasta crnike (S1. 1D). Radi se o efemernoj vrsti, koja u suhom dijelu godine potpuno iščezava sa staništa, te stoga ostaje uglavnom nezamijećena.

\section{Riccardia incurvata Lindb.}

Mjesto prvog objavljivanja: Bot. Not. 1878: 187

Sinonimi: Aneura incurvata (Lindb.) Steph., Hedwigia 32(3): 137 (1893)

Nalazišta u Hrvatskoj: cret Jarak (Park prirode Žumberak-Samoborsko gorje) (preuzeto iz Alegro i sur. 2015a)

Ovo je borealno-montana jetrenjarka, poznata s Balkanskog poluotoka tek iz Crne Gore, Albanije, Srbije i Sjeverne Makedonije. U Hrvatskoj je zabilježena na bazofilnom cretu Jarak kraj Sošica s još nekoliko rijetkih vrsta mahovina.

\section{Ricciocarpos natans (L.) Corda}

Mjesto prvog objavljivanja: Naturalientausch 12: 651 (1829)

Sinonimi: Riccia capillata Schmidel, Icon. P1., ed. Palm 3: 276 (1797); R. natans L., Syst. Nat. (ed. 10) 2: 1339 (1759); R. velutina Wilson ex Hook., Icon. Pl. 3: pl. 249 (1840); Ricciocarpos velutinus (Wilson ex Hook.) Steph., Sp. Hepat. (Stephani) 1: 55 (1898)

Nalazišta u Hrvatskoj: Drava (Struga), ribnjaci Podunavlje, Mali Sakadaš (Kopačevo), Sakadaš, potok Rakovica (Donji Vidovec, Kotoriba), Slatina (Novi Senkovac) (preuzeto iz Šegota i sur. 2020b)

Ovo je amfibijska vrsta jetrenjarke, koja može živjeti u akvatičkoj i terestričkoj formi. U Hrvatskoj je u razdoblju od 2006. do 2016. zabilježena na šest lokaliteta u istočnoj i sjevernoj Hrvatskoj, uglavnom u poplavnim područjima, rukavcima i mrtvicama Dunava, Drave i Mure. Vrsta preferira male i plitke eutrofne stajaćice s ostalim flotantnim makrofitima (Sl. 1E).

\section{Andreaea rothii F. Weber et D. Mohr ssp. rothii}

Mjesto prvog objavljivanja: Bot. Taschenbuch 386. pl. 11: f. 7-8 (1807)

Sinonimi: A. rothii F. Weber et D. Mohr var. hamata Lindb., Brit. Moss Fl. 1: 14; A. rupestris Weber et D. Mohr var. hamata (Lindb.) Par., Index Bryol. 33. (1894)

Nalazišta u Hrvatskoj: Papuk, Sokolina, iznad potoka Stražemanka (preuzeto iz Cziky i sur. 2016)

Ova borealno-tempratna, suboceanska vrsta u Hrvatskoj je prvi puta pronađena 2015. godine na lokalitetu Sokolina u blizini sela Doljanci na Papuku, na nadmorskoj visini od $539 \mathrm{~m}$ (Sl. 1F). Vrsta raste na sjevernoj ekspoziciji gotovo okomite gnajsne stijene gdje zauzima površinu od oko jednog kvadratnog metra. Zbog izrazito male populacije koja se nalazi pod prijetnjom stanišnih promjena za ovu vrstu preložen je status kritično ugrožene svojte. Vrsta je rijetka u čitavoj jugoistočnoj Europi, te su njena nalazišta bila poznata jedino iz Slovenije, Srbije i Rumunjske. Pripada evolucijski vrlo izoliranoj liniji unutar pravih mahovina, koju između ostalog karakterizira otvaranje tobolaca uzdužnim pukotinama, a ne pomoću poklopčića i peristomijalnih zubića, što je zajednička karakteristika ostalih pravih mahovina.

\section{Bucklandiella affinis (Schleich. ex F. Weber et D. Mohr) Bednarek-Ochyra et Ochyra}

Mjesto prvog objavljivanja: Biodivers. Poland 3 (2003) Sinonimi: Racomitrium affine (Schleich ex F. Weber et D. Mohr) Lindb., Acta Soc. Sci. Fenn. 10: 552 (1875)

Nalazišta u Hrvatskoj: Papuk, Sokolina (preuzeto iz Deme i Csiky 2018) 
Ova europska tempratna vrsta je u Hrvatskoj prvi put pronađena 2017. na lokalitetu Sokolina na Papuku. Isključivo sterilne jedinke pronađene su na metamorfnim stijenama (gnajsu) na rubu acidotermofilne šume hrasta kitnjaka.

\section{Buxbaumia aphylla Hedw.}

Mjesto prvog objavljivanja: Sp. Musc. Frond. 166 (1801)

Sinonimi: Buxbaumia vulgaris Brid., Bryol. Univ. 1: 329 (1826)

Nalazišta u Hrvatskoj: Papuk (Konjska smrt, Sokolina i Svinjarevac) (preuzeto iz Deme i sur. 2017)

Rijetka cirkumpolarna borealno-montana vrsta pronađena je tijekom 2015. i 2016. na tri lokaliteta na Papuku (Sl. 1G). Vrsta je rasla na golom kiselom tlu, a na lokalitetu Svinjarevac i na tresetu. Vrlo slična i u Hrvatskoj također relativno rijetka vrsta $B$. viridis raste isključivo na mrtvom drvu.

\section{Campylopus introflexus (Hedw.) Brid.}

Mjesto prvog objavljivanja: Muscol. Recent. Suppl. 4: 72 (1819)

Sinonimi: Dicranum introflexum Hedw., Sp. Musc. Frond. 147. 29 (1801)

Nalazišta u Hrvatskoj: Vrhovinsko polje u Lici i Sokolina na Papuku (preuzeto iz Alegro i sur. 2018a)

Ovo je prva invazivna vrsta mahovine zabilježena u Hrvatskoj. Prvi puta je pronađena 2013. na Vrhovinskom polju u Lici gdje je rasla na krpama otvorenog tla te na kori otpaloj s trupaca borova odloženih u blizini (Sl. 1H). Drugi puta je zabilježena na Papuku, na lokalitetu Sokolina kod sela Doljanci gdje su pronađene i druge nove ili rijetke vrste mahovina u flori Hrvatske. Vrsta je tu rasla na otvorenoj terasi gnajsne stijene, na rubu acidotermofilne sastojine hrasta kitnjaka. Obje populacije su male i zajedno ne zauzimaju više od nekoliko kvadratnih metara. Na temelju ovih nalaza procijenjeno je da je opasnost od invazije ove vrste u Hrvatskoj niska s obzirom na njene ekološke preferencije i raspoloživa staništa. Međutim, potreban je oprez i praćenje stanja. Vrsta je iz Južne Amerike u Europu prvi puta unesena 1941. vjerojatno kao zaštita za krhke predmete u brodskim transportnim sanducima. U atlantskim dijelovima Europe mjestimice se znatno rasprostranila i čini ekološku štetu, osobito u zajednicama pješčanih morskih obala.

\section{Conardia compacta (Drumm. ex Müll.} Hal.) H. Rob.

Mjesto prvog objavljivanja: Phytologia 33(4): 295 (1976)

Sinonimi: Amblystegium compactum (Müll. Hal.) Austin, Musci Appalach. 372 (1870); A. densum Milde, Bot. Zeitung (Berlin) 22(19) Beil.: 21 (1864); Brachythecium densum (Milde) Jur., Bryoth. Eur. 20: n. 995 (1867); Hypnum densum (Milde) Milde, Bryol. Siles. 360 (1869); Rhynchostegiella compacta (Müll. Hal.) Loeske, Stud. Morph. Laubm. 182 (1910)

Nalazišta u Hrvatskoj: Plitvička jezera (preuzeto iz Alegro i sur. 2019)

Ovo je cirkumpolarna, borealno-montana vrsta rijetka u jugoistočnoj Europi. Pronađena je 2016. na vlažnim sedrenim stijenama van tekuće vode koje poput amfiteatra okružuju južnu obalu jezera Okrugljak. Populacija je izrazito mala i čine ju malobrojne, sitne skupine stabalaca.

\section{Cynodontium tenellum (Schimp.) Limpr.}

Mjesto prvog objavljivanja: Krypt.-Fl. Schlesien 1: 425 (1877)

Sinonimi: C. gracilescens (F. Weber et D. Mohr) Schimp. var. tenellum Schimp., Coroll. Bryol. Eur. 12 (1856); C. torquescens Limpr., Laubm. Deutschl. 1: 288 (1886); Oncophorus torquescens Lindb. \& Arnell, Kongl. Svenska Vetensk. Acad. Handl. 23(10): 92 (1890)

Nalazišta u Hrvatskoj: Vrh Mališćak (Park prirode Papuk) (preuzeto iz Alegro i sur. 2019) 
Vrsta je pronađena 2016. na istočnim padinama vrha Mališćak, unutar acidotermofilne šume hrasta kitnjaka (Quercus petrea (Matt.) Liebl.) razvijene na strmim silikatnim stijenama i osulinama. Ovo je vrsta cirkumpolarne rasprostranjenosti i borealnog arktičko-montanog elementa. Dosad je zabilježena u zemljama sjeverne, srednje i jugoistočne Europe.

\section{Drepanium fastigiatum (Brid.) C. E. 0. Jensen}

Mjesto prvog objavljivanja: Meddel. Grønland 3: 326 (1887)

Sinonimi: Hypnum recurvatum (Lindb. \& Arnell) Kindb., Enum. Bryin. Exot., Suppl. 2: 100 (1893); Drepanium recurvatum (Lindb. \& Arnell) G.Roth, Enum. Bryin. Exot., Suppl. 2: 100 (1893); Stereodon recurvatus Lindb. \& Arnell, Svenska Vetensk. Acad. Handl. 23(10): 149 (1890); Hypnum bridelianum $\mathrm{H}$. A. Crum, Steere \& L. E. Anderson, 68: 433 (1965 [1966]); H. cupressiforme Hedw. var. fastigiatum Hampe, Flora 20: 274 (1837); H. fastigiatum Brid., Bryol. Univ. 2: 620 (1827); H. ravaudii Boulay ssp. fastigiatum (Brid.) Wijk \& Margad, Taxon 9: 51 (1960)

Nalazišta u Hrvatskoj: Premužićeva staza na Sjevernom Velebitu (preuzeto iz Šegota i sur. 2020a)

Ova cirkumholarktička vrsta u Europi je ograničena na borealni pojas, s rijetkim i disjunktnim populacijama na planinama srednje i južne Europe. U jugoistočnoj Europi je dosad zabilježeno tek nekoliko nalaza u Sjevernoj Makedoniji, Srbiji, Crnoj Gori, Sloveniji, Grčkoj, Bugarskoj i na Kosovu. Dvije populacije duž Premužićeve staze otkrivene su 2014 . i 2015. unutar vegetacije klekovine bora krivulja (Sl. 1I). Vrsta je epifilna, kalcifilna i semiskiofilna (raste priljubljena uz vapnenačke stijene ispod grmova bora krivulja).

Dichodontium flavescens (Dicks.) Lindb. Mjesto prvog objavljivanja: Bot. Not. 1878: 113 (1878)
Sinonimi: Dichodontium pellucidum (Hedw.) Schimp. var. flavescens (Dicks. ex With.) Moore, Proc. Roy. Irish Acad. 1: 349 (1873); Dichodontium flavescens (Dicks.) Lindb. var. viridis Hérib., Mém. Acad. Sci. Clermont-Ferrand 14: 401 (1899)

Nalazišta u Hrvatskoj: rijeke Čabranka i Kupa (Gorski kotar) (preuzeto iz Alegro i sur. 2019)

U Hrvatskoj je po prvi puta zabilježena 2016. na većim karbonatnim stijenama na obalama brzog i hladnog gornjeg toka Kupe te manje gorske rijeke Čabranke i to u zoni koja je periodično pod vodom. Vrsta je suboceansko-montana te je dosad zabilježena u mnogim europskim zemljama, dok je u jugoistočnoj Europi zabilježena samo u Crnoj Gori i Rumunjskoj. Vrlo je slična vrsti Dichodontium pellucidum (Hedw.) Schimp., a razlike u morfologiji listića uočavaju se tek pod mikroskopskim povećanjem kad postaje jasno da $D$. flavescens ima šiljast vrh listića, a rub lista je u vršnom dijelu snažnije i nepravilnije nazubljen. Bitno je odrediti i omjer duljine i širine listića, koji je kod $D$. flavescens veći i iznosi 4,1-5,5. Obje vrste dolaze u sličnim stanišnim uvjetima, a neki autori $D$. flavescens tretiraju kao podvrstu - D. pellucidum subsp. flavescens.

\section{Fissidens fontanus (Bach. Pyl.) Steud.}

Mjesto prvog objavljivanja: Nomencl. Bot. 2: 166 (1824)

Sinonimi: Conomitrium julianum (Savi ex DC.) Mont., Ann. Sci. Nat., Bot., sér. 2, 8: 246 (1837)

Nalazišta u Hrvatskoj: rijeka Trepča i Visovačko jezero (preuzeto iz Alegro i sur. 2019 i Šegota i sur. 2019)

Ovo je vodena europska tempratna vrsta, koja je u jugoistočnoj Europi izrazito rijetka. Dosad je zabilježena tek u Rumunjskoj, Bugarskoj i Sloveniji, a nedavno i u Grčkoj (otok Lezbos) i u Crnoj Gori. U Hrvatskoj je pronađena u rijeci Trepči na Banovini i u Visovačkom jezeru u Nacionalnom parku Krka (Sl. 1J). 
Homalothecium meridionale (M. Fleisch. et Warnst.) Hedenäs

Mjesto prvog objavljivanja: Taxon 63(2) (2014)

Nalazišta u Hrvatskoj: Omiš, stijene iznad grada s lijeve stane Cetine (preuzeto iz Sabovljević i sur. 2015)

Ova nedavno opisana vrsta iz roda Homalothecium pronađena je 2013. u vegetaciji otvorenih karbonatnih stijena iznad grada Omiša, na padini podno Fortice. Vjerojatno je šire rasprostranjena u Hrvatskoj, no za pouzdanu determinaciju su potrebni tobolci koji se ne javljaju redovno.

\section{Microhypnum sauteri (Schimp.) Kučera et Ignatov}

Mjesto prvog objavljivanja: Taxon 68(4): 649 (2019)

Sinonimi: Hypnum sauteri Schimp., Flora 33: 445 (1850); Drepanium sauteri (Schimp.) G.Roth, Eur. Laubm. 2: 614 (1904); Hypnum fastigiatum Brid. subsp. sauteri (Schimp.) Molendo, Ber. Naturhist. Vereins Augsburg 18: 184 (1865); Stereodon sauteri (Schimp.) H. A. Möller, Bot. Not. 1907: 145 (1907)

Nalazišta u Hrvatskoj: Snježnik (preuzeto iz Šegota i sur. 2020a)

Rijetka europska endemična i reliktna vrsta s borealno-alpskim arealom (Alpe, Karpati, Jursko gorje i Norveška). U jugoistočnoj Europi postoje vrlo rijetki i često stari nalazi u Sloveniji, Bugarskoj, Kosovu i Sjevernoj Makedoniji. Tijekom 2015. otkrivene su dvije populacije na Snježniku, jedna u smrekovoj šumi uz Frankopanski put, a druga na hrptu Snježnika u klekovini bora krivulja (Sl. 1K). Vrsta je morfološki i ekološki (kalcifilna i epilitska) slična vrsti Drepanium fastigiatum.

\section{Myurella sibirica (Müll. Hal.) Reimers}

Mjesto prvog objavljivanja: Hedwigia 76: 292 (1937)

Sinonimi: Hypnum sibiricum Müll. Hal., Syn. Musc. Frond. 2(7/8): 418 (1851)

Nalazišta u Hrvatskoj: izvor Kupe (Gorski kotar) (preuzeto iz Alegro i sur. 2018b)
Ova istočno-subarktičko-alpska vrsta široko je rasprostranjena u planinama južnog Sibira, Kine, Japana i na Himalaji, no rijetka je u Europi. Pronađena je u pukotinama trajno zasjenjenih i vlažnih vapnenačkih stijena koje okružuju izvor Kupe (Sl. 1L). Populacija je u dobrom stanju s obzirom na razvijenost i stanje jedinki, a čini ju nekoliko desetaka nakupina od po nekoliko kvadratnih centimetara. U odnosu na druga europska nalazišta ovo se ističe najmanjom nadmorskom visinom i najvišim temperaturnim pokazateljima okolnog područja. To upućuje da je ova vrsta u vrlo specifičnim mikroklimatskim uvjetima izvora Kupe ovdje zaostala kao glacijalni relikt. Na temelju prikupljenih podataka procijenjena je kao osjetljiva (VU) svojta u flori Hrvatske.

\section{Orthotrichum philibertii Venturi}

Mjesto prvog objavljivanja: Rev. Bryol. 5: 45 (1878)

Sinonimi: O. pumilum Sv. ex anon var. philibertii Venturi, Muscol. Gall. 180: 23 (1887); O. schimperi Hammar var. philibertii (Venturi) Boulay, Musc. France, Mousses 339 (1884)

Nalazišta u Hrvatskoj: Sjeverni Velebit (preuzeto iz Alegro i sur. 2019)

Ova oceansko-mediteranska montana vrsta poznata je iz većine sredozemnih zemalja, no na Balkanskom je poluotoku zabilježena samo u Grčkoj, Rumunjskoj i Srbiji. Vrsta je pronađena na Sjevernom Velebitu u termofilnim sastojinama bijelog i crnog graba na putu od Jablanca prema Alanu na kori stabala klena (Acer monspessulanum L.) i medunca (Quercus pubescens Willd.).

\section{Physcomitrium eurystomum Sendtn.}

Mjesto prvog objavljivanja: Denkschr. Bayer. Bot. Ges. Regensburg 3: 142 (1841)

Sinonimi: Gymnostomum acuminatum Schleich., Cat. Pl. Helv. (ed. 4) 40 (1821); Ph. acuminatum Bruch \& Schimp., Bryol. Eur. 3: 247 (1841); Ph. sphaericum (C. F. Ludw. ex Schkur.) Brid. var. eurystomum (Sendtn.) Husn., Fl. Mousses Nord. 
Ouest (ed. 2) 101 (1882); Ph. sphaericum (C. F. Ludw. ex Schkur.) Brid. var. major Boulay, Musc. France, Mousses 303 (1884)

Nalazišta u Hrvatskoj: Biljsko jezero (Baranja) (preuzeto iz Rimac i sur. 2019b)

Vrsta je pronađena 2017. na pješčanim, nježno položenim obalama jezera Bilje, starog meandra rijeke Drave (S1. 1M). Ova efemerna vrsta preferira rubove jezera, akumulacija, rezervoara, a rjeđe dolazi i duž obala rijeka. Na ovim staništima nastanjuje zonu povlačenja vode koja ostaje na suhom za vrijeme nižih ljetnih vodostaja. Tada efemerne vrste u vrlo kratkom razdoblju uspijevaju dovršiti čitav životni ciklus, a sljedeće povoljno razdoblje dočekat će kao dugoživuće i otporne spore zaštićene u sedimentu. Vrsta pripada euroazijskom tempratnom elementu, a iako je bilježena diljem Europe, relativno je rijetka.

\section{Physcomitrium sphaericum (C. F. Ludw. ex Schkur.) Brid.}

Mjesto prvog objavljivanja: Bryol. Univ. 2: 815 (1827)

Sinonimi: Gymnostomum sphaericum C.F. Ludw. ex Schkuhr Deutschl., Krypt. Gew. 2(1): 26 (1810); Ph. sphaericum (C. F. Ludw. ex Schkur.) Brid. var. minor Boulay, Musc. France, Mousses 304 (1884)

Nalazišta u Hrvatskoj: rijeka Garešnica, Garešnica (preuzeto iz Rimac i sur. 2020)

Ova malena efemerna vrsta pronađena je 2019. na pješčanim obalama nizinske rijeke Garešnice $u$ vegetaciji niskih šiljeva (Nanocyperion Koch 1926). Kao i ostale efemerne mahovine obalnih staništa, ova vrsta razvija se ljeti i u ranu jesen kada obala uslijed sniženja razine vode ostaje na suhom, ali je muljevita ili pjeskovita podloga i dalje vlažna. Izrazito je malena mahovina, čije su rozete zajedno $s$ razvijenim sporofitom visoke tek $4 \mathrm{~mm}$. Pripada euroazijskom tempratnom elementu, rasprostranjena je diljem Europe, no u jugoistočnoj Europi je rijetko bilježena.

\section{Pseudoleskeella rupestris (Berggr.) Hedenäs et L. Söderstr.}

Mjesto prvog objavljivanja: Lindbergia 17: 64 (1991)

Sinonimi: P. catenulata (Brid. ex Schrad.) Schimp. var. acuminata (Culm.) Crundw., Trans. Brit. Bryol. Soc. 2: 278 (1956); Pseudoleskea catenulata (Brid. ex Schrad.) Schimp. var. subtectorum Thér., Rev. Bryol. 25: 28 (1898); P. sibirica (Arnell) P. S. Wilson \& D. H. Norris, Bryologist 92: 390 (1989); P. catenulata (Brid. ex Schrad.) Kindb. var. acuminata (Culm.) J. J. Amann, Fl. Mouss. Suisse 2: 287 ( 1918); Leskea rupestris Berggr., Acta Univ. Lund. 2 Afd. 3(7): 9 (1866); L. subtectorum Thér, Zprávy Komis. Přír. Výzk. Moravy Slezska Odděl. Bot. 2: 69 (1906)

Nalazišta u Hrvatskoj: Sopotski slap (Park prirode Žumberak-Samoborsko gorje) (preuzeto iz Alegro i sur. 2015a)

Ova cirkumpolarna borealno-montana vrsta rasprostranjena je po cijeloj Europi, no rijetka je na Balkanskom poluotoku. Recentno je zabilježena u Crnoj Gori, Albaniji i Srbiji. U Hrvatskoj je prvi put zabilježena na zasjenjenim vapnenačkim stijenama uzduž Sopotskog slapa u Parku prirode ŽumberakSamoborsko gorje.

\section{Rhabdoweisia crispata (Dicks.) Lindb.}

Mjesto prvog objavljivanja: Acta Soc. Sci. Fenn. 10: $22(1871)$

Sinonimi: Rh. denticulata Bruch \& Schimp., Bryol. Eur. 1: 99 (1846); Weissia denticulata Brid., Muscol. Recent. Suppl. 1: 108 (1806); Weissia fugax Hedw. var. subdenticulata Boulay, Musc. France, Mousses $543(1884)$

Nalazišta u Hrvatskoj: kod Vranovog vrha iznad potoka Šumećice na Papuku (preuzeto iz Alegro i sur. 2019).

Ovo je oceanska borealno-montana vrsta rasprostranjena uglavnom u sjeverozapadnoj i srednjoj Europi dok je na jugoistoku vrlo rijetka i poznata jedino iz Rumunjske i Bugarske. Pronađena je 2016. na 
Papuku, u podnožju visoke okomite silikatne stijene koja izdiže iznad potoka Šumećice unutar acidofilne bukove šume. Vrsta raste na trajno zasjenjenom i vlažnom mikrostaništu, na nekoliko milimetara debelom sloju glinovitog tla koje prekriva matičnu stijenu. Čini rahle prostirke koje ukupno zauzimaju površinu manju od kvadratnog metra.

\section{Schistidium trichodon (Brid.) Poelt var. trichodon}

Mjesto prvog objavljivanja: Svensk Bot. Tidskr. 47: 253 (1953)

Sinonimi: S. apocarpum (Hedw.) Bruch \& Schimp. subsp. longidens (Philib.) Wijk \& Margad, Taxon 9: $191(1960)$

Nalazišta u Hrvatskoj: između Slanog dola i Gradišća na Samoborskom gorju (preuzeto iz Alegro i sur. 2019)

Borealno je montana vrsta rasprostranjena u sjevernoj, srednjoj i dijelom istočnoj Europi, dok je na balkanskom području rijetka, odnosno dosad nedovoljno istražene rasprostranjenosti. Pronađena je na zasjenjenim karbonatnim stijenama uz cestu koja vodi od Slanog dola prema Gradišću (Sl. 10), unutar šume u kojoj dominira kitnjak, a velika zastupljenost borovnice (Vaccinium myrtillus L.) u sloju niskog grmlja upućuje na zakiseljenost podloge. Vrsta nije česta u vegetaciji stijena tog područja, ali dolazi u rastresenim, pojedinačnim busenčićima.

\section{Syntrichia norvegica F. Weber}

Mjesto prvog objavljivanja: Arch. Syst. Naturgesch. 1(1): 130 (1804)

Sinonimi: S. ruralis (Hedw.) F. Weber \& D. Mohr var. norvegica (F. Weber) Steud., Nomencl. Bot. 2: 406 (1824); Tortula aciphylla (Bruch \& Schimp.) Hartm., Handb. Skand. Fl. (ed. 5) 381 (1849); T. norvegica (F. Weber) Lindb., Öfvers. Förh. Kongl. Svenska Vetensk.-Akad. 21: 245 (1864); T. ruralis (Hedw.) G. Gaertn., B. Mey. \& Scherb. var. alpina Wahlenb.,
Fl. Carpat. Princ. 338 (1814); T. ruralis (Hedw.) G. Gaertn., B. Mey. \& Scherb. subsp. norvegica (F. Weber) Dixon, Stud. Handb. Brit. Mosses (ed. 3) 204 (1924);, Barbula aciphylla Bruch \& Schimp., Bryol. Eur. 2: 104 (1842), B. norvegica (F. Weber) Lindb., Öfvers. Förh. Kongl. Svenska Vetensk.-Akad. 20: 387 (1863)

Nalazišta u Hrvatskoj: Rožanski kukovi, Sjeverni Velebit (preuzeto iz Alegro i sur. 2015b)

Ovo je cirkumpolarna arktičko-montana vrsta koja se rijetko nalazi na nižim nadmorskim visinama i u južnoj Europi. Vrsta je prvi puta pronađena 2014. na dnu Puževe doline (Sl. 1N), duboke vrtače u Rožanskim kukovima u neposrednoj blizini Rossijeve kolibe na visini od $1540 \mathrm{~m} \mathrm{n}$. m. Vrsta je rasla u frigofilnoj zajednici Drepanoclado uncinati-Heliospermetum pusillae i okolnoj šikari valdštajnove vrbe (Salicetum waldsteinianae) čineći mozaične prostirke od nekoliko desetaka kvadratnih centimetara. Zanimljivo je da je tu i u Hrvatskoj jedino poznato nalazište arkto-alpske vrste Cyrtomnium hymenophylloides (Huebener) T. J. Kop. Kasnijih godina vrsta je pronalažena i u klekovini bora krivulja, također na području Rožanskih kukova, također u jastučićima i prostirkama rijetko većim od desetak kvadratnih centimetara. Na temelju tih nalaza može se zaključiti da tvori stabilnu populaciju na tom području, iako vrlo izoliranu od drugih najbližih populacija.

\section{Tortella fasciculata (Culm.) Culm.}

Mjesto prvog objavljivanja: Rev. Bryol. et Lichénologique 10: 6 (1937)

Sinonimi: T. bambergeri auct., non (Schimp.) Broth. p.p., Nat. Pflanzenfam. I(3): 397 (1902); T. tortuosa (Schrad. ex Hedw.) Limpr. subsp. fasciculata Culm., Rev. Bryol. 51: 22 (1924)

Nalazišta u Hrvatskoj: Pliš na Papuku u blizini sela Velika; Čorkova uvala i uz jezero Okrugljak unutar Nacionalnog parka Plitvička jezera (preuzeto iz Alegro i sur. 2019) 

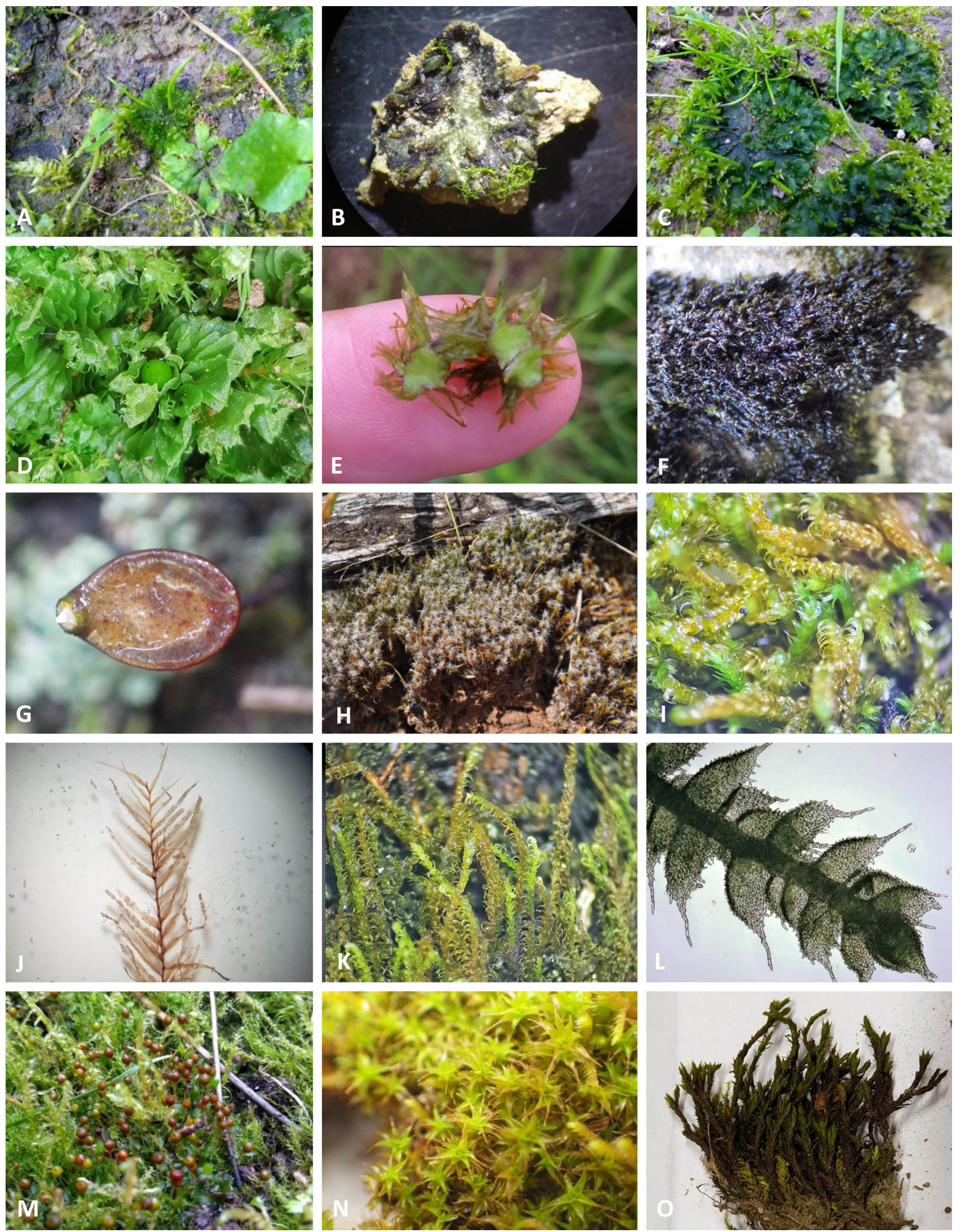

Slika 1. Nove svojte mahovina u Hrvatskoj: Anthoceros agrestis (A), Notothylas orbicularis (B), Phaeoceros carolinianus (C), Petalophyllum ralfsii (D), Ricciocarpos natans (E), Andreaea rothii ssp. rothii (F), Buxbaumia aphylla (G), Campylopus introflexus (H), Drepanium fastigiatum (I), Fissidens fontanus (J), Microhypnum sauteri (K), Myurella sibirica (L), Physcomitrium eurystomum (M), Syntrichia norvegica (N), Schistidium trichodon var. trichodon $(\mathrm{O})$. 
Ova vrsta pripada kompleksu vrsta T. tortuosa, koje su međusobno vrlo slične i često problematične za razlikovanje, tako da je njena rasprostranjenost $u$ cijelom arealu nedovoljno poznata. Taksonomska revizija (Köckinger \& Hedenäs 2017) je pokazala da se unutar vrste dotad shvaćene kao T. bambergeri auct. mogu razlikovati dvije vrste, T. fasciculata $i T$. pseudofragilis. To nas je navelo na reviziju herbarijskog materijala određenog kao T. bambergeri. Revizija je pokazala da se uzorci sabrani na Plišu na Papuku 2011., te u Čorkovoj uvali 2013. i stijenama oko jezera Okrugljak 2016. na Plitvičkim jezerima mogu pribrojiti vrsti T. fasciculata na temelju postojanja središnjeg snopa u stabalcu i središnjeg rebra koje je u gornjem dijelu listića prekriveno izodijametričnim stanicama. $\mathrm{Na}$ oba područja vrsta je pronađena na uglavnom zasjenjenim vapnenačkim stijenama, na Papuku unutar termofilnih šuma s hrastom kitnjakom i meduncem, uz Okrugljak unutar termofilnih šikara s crnim grabom, a u Čorkovoj uvali unutar šume bukve i jele. Prema dosadašnjim spoznajama T. fasciculata je termofilna vrsta suboceansko-submediteranskog flornog elementa, a njezinu termofilnost potvrđuju dva od tri opisana lokaliteta.

\section{Zygodon conoideus (Dicks.) Hook. et Taylor}

Mjesto prvog objavljivanja: Muscol. Brit. 71: 21 (1818)

Sinonimi: Bryum conoideum Dicks., Fasc. Pl. Crypt. Brit. 4: 9 (1801); Z. brebissoni Bruch \& Schimp., Bryol. Eur. 3: 40 (1838)

Nalazišta u Hrvatskoj: Rt Zaglavić zapadno od mjesta Mala Rava, otok Rava (preuzeto iz Sabovljević i sur. 2018)

Vrsta je u Hrvatskoj prvi put zabilježena 2014. na kori maslina u masliniku na otoku Ravi. Vrsta ima uglavnom atlantsko-mediteransku rasprostranjenost, a opaženo je i nedavno širenje u srednjoj Europi. Ova vrsta raste u malim čupercima na kori listopadnog drveća, kao uostalom i mnoge druge mahovine. Vrsta se prepoznaje prema izgledu listića i prisutnosti gema koje su cilindrične i građene od pet do osam stanica.

\section{Literatura}

Alegro, A., Šegota, V., Papp, B. (2015a): Contribution to the bryophyte flora of Croatia IV. Žumberačka gora Mt. Studia botanica hungarica 46(1): 1-20. Alegro, A., Šegota, V., Papp, B. (2015b): New national and regional records 44: Syntichia norvegica F. Weber. Journal of Bryology 37(3): 236-236. Alegro, A., Šegota, V., Papp, B., Deme, J., Kovacs, D., Purger, D., Csiky, J. (2018a): The invasive moss Campylopus introflexus (Hedw.) Brid. (Bryophyta) spreads further into South-Eastern Europe. Cryptogamie bryologie 39(3): 331-341.

Alegro, A., Šegota, V., Rimac, A., Kiebacher, T., Prlić, D., Sedlar, Z., Vuković, N., Papp, B. (2019): New and noteworthy bryophyte records from Croatia. Cryptogamie, Bryologie 40(2): 5-13.

Alegro, A., Šegota, V., Vuković, N., Papp, B. (2018b): Myurella sibirica in Croatia, new finding in southeastern Europe. Herzogia 31(2): 782-790.

Csiky, J., Kovács, D., Purger, D., Alegro, A. L., Šegota, V., Deme, J. (2016): New national and regional bryophyte records 48: Andreaea rothii F. Weber \& D. Mohr subsp. rothii. Journal of Bryology 38(3): 235-259.

Deme, J., Alegro, A., Kovács, D., Purger, D., Šegota, V., Csiky, J. (2017): New national and regional bryophyte records. 52: Buxbaumia aphylla Hedw. Journal of Bryology 39(3): 289-289.

Deme, J., Csiky, J. (2018): New national and regional bryophyte records. 56: Bucklandiella affinis (F.Weber \& D.Mohr) Bedn.-Ochyra \& Ochyra. Journal of Bryology 40(3): 273-274.

Rimac, A., Alegro, A., Vuković, N., Koletić, N., Šegota, V. (2020): New national and regional bryophyte records. 62: Physcomitrium sphaericum (C. F. Ludw. ex Schkuhr) Brid. Journal of Bryology 42(2): 195-208.

Rimac, A., Šegota, V., Alegro, A., Koletić, N., Vuković, N. (2019a): Novelties in the hornwort flora of Croatia and Southeast Europe. Cryptogamie, Bryologie 40(22): 289-295. 
Rimac, A., Šegota, V., Alegro, A., Koletić N., Vuković N., Papp B. (2019b): New and noteworthy bryophyte records from lacustrine drawdown zones in Croatia. Herzogia 32(2): 315-325.

Sabovljević, M., Kuzmanović, N., Vreš, B., Ruščić, M., Surina, B. (2018): Contribution to the bryophyte flora of the island of Rava (Adriatic Sea, Mediterranean) and Zygodon conoideus new to Croatia. Herzogia 31(2): 998-994.

Sabovljević, M., Pantović, J., Sabovljević, A. D. (2015): New national and regional bryophyte records. 45: Homalothecium mediterraneum Hedenäs. Journal of Bryology 39(3): 314-314.

Šegota, V., Alegro, A., Ozimec, S., Vuković, N., Koletic, N., Prlić, D., Bontek, M. (2017): New national and regional bryophyte records. 52: Ricciocarpos natanas (L.) Corda. Journal of Bryology 39(3): 295-296.

Šegota, V., Gulin, I., Rimac, A., Alegro, A. (2019): Contribution to bryophyte flora of Croatia: new finding of rare aquatic moss Fissidens fontanus (Bach. Pyl.) Steud. in Lake Visovac (Krka National Park). Natura Croatica 28(1): 63-71.

Šegota, V., Rimac, A., Dragićević, S., Koletić, N., Alegro, A. (2020a): Drepanium fastigiatum (Brid.) C. E. O. Jensen and Microhypnum sauteri (Schimp.) Kučera \& Ignatov new for Croatia. Herzogia 33(2): 291-299.

Šegota, V., Rimac, A., Koletić, N., Vuković, N., Alegro, A. (2020b): Elucidating distributional and ecological patterns of the rare Mediterranean-Atlantic species Petalophyllum ralfsii (Wills.) Nees \& Gotsche in Europe following its first record on the Adriatic coast (Croatia). Herzogia 33(2): 275-290. 